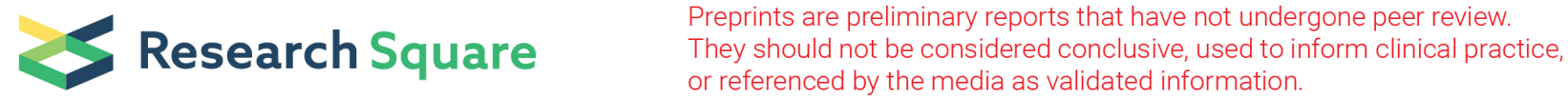

\section{A validation study of Perceived Social Support (PSS) of chronic patients in Antiretroviral clinics}

Abdilahi Yousuf ( $\square$ abdiy207@gmail.com )

Jijiga University https://orcid.org/0000-0003-2183-2183

\section{Ramli Musa}

IIUM https://orcid.org/0000-0003-1651-2775

Muhammad Lokman Md. Isa

IIUM https://orcid.org/0000-0001-8063-3526

SitiRoshaidai Mohd Arifin

IIUM https://orcid.org/0000-0002-2041-2382

\section{Research Article}

Keywords: Perceived Social Support, WLHIV, PLWHIV, depression

Posted Date: November 20th, 2020

DOI: https://doi.org/10.21203/rs.3.rs-112013/v1

License: (9) This work is licensed under a Creative Commons Attribution 4.0 International License.

Read Full License 


\section{Abstract}

Background: Perceived Social Support which referred to an individual's extent of satisfaction regarding his/her necessary support, information, and interactions. According to (Procidano, 1983), PSS is a key element for understanding supportive behavior and is assumed to determine its association with depression. This 12-item scale is considered a substantial component that influences the emotional wellbeing of chronic patients. Hence, this paper is intended to validate the English version of Perceived Social Support among WLHIV.

Methods: A facility-based cross-sectional study was conducted in WLHIV who attends the ART treatment of selected hospitals. A total of 357 attendees were recruited for a broader mixed-method designed study. The English version of PSS was translated into a national Somali language. The internal consistency was measured to analyze the reliability and Principle Component Analysis (PCA) was used to determine the validity of the study.

Results: The findings of this study reveals that the PSS has shown a good internal consistency with Cronbach alpha greater than 0.60 . Based on the principle component analysis, the validity construct of the scale was also measured showing a Varimax rotation of the components was successfully loaded and eigenvalue was greater than 1.

Conclusion: This version, Perceived Social Support (PSS) is fit to be introduced in the health institutions for screening the level of support of chronic patients particularly its suitability for applications in the ART treatment services.

\section{Introduction}

In recent year, there has been an increasing amount of literature which report that Perceived Social Support (PSS) as one of the main factors affecting the quality of life and survivorship in PLHIV (2). This support represents interpersonal resources regarding the provision of supportive interaction which is either by emotional support, material support, informational support, or appraisal support to an individual who needs to remain healthy or adjust to the stressful events. The relation between Perceived Social Support and depression has been long studied. Thus, recent studies have shown that Social Support is one of the common psychosocial factors associated with depression in HIV patients, and problems related to social interaction not only affects the extent of depression in PLHIV but also has an impact on HIV disease progression and treatment adherence.

In general, depression is found to be one of the main health problems faced by chronic patients like hypertension, diabetic (3) or other infectious diseases like HIV or COVID-19 (4). Frontline health care providers should be sensitized screening of depression of chronic patients. 
Moreover, due to the presence of health concerns among the adult out-patients, screening and diagnosis of depression become crucial in the health care set up. Thus, numerous validation studies have been carried out to introduce mental health related interventions like depression screening to identify chronic patients with severe depression from the mild depressed patients $(5,6)$. Apart from the available the assessment of the psychometric properties of the commonly available screening tools (7-9), the validation of the Perceived Social Support would play an important role in the identification of the apparent psychological and social assistance of the chronic patients enrolled in the antiretroviral clinics.

Despite more recently, the adult population-based surveys have recognized that PSS is a significant influencing factor to the level of depression for social and psychological reasons, yet, the pre-existing scale is not validated in the local context. Hence, this validation study is intended to test the reliability and measure the validity constructs of the PSS scale on WLHIV in Ethiopia.

\section{Methods}

\section{Questionnaire}

A team of health professionals assigned from the two regional hospitals has thoroughly carried-out the translation process. The assigned group encompassed a psychiatrist, public health officer, and a consoler nurse. For an appraisal of the wording patterns, contextual explanations, and cultural reflections, a team from Jijiga University has reviewed and approved the final version.

\section{Data collection procedure}

After written informed consent was signed and participants were explained about the study purposes and procedures. Participants were also asked to complete the questionnaire and the screening assessment took an average of 15 minutes. Once finalized, the principal investigator was instantly checking its completeness. A higher recorded rank demonstrated a higher score of PSS. The screening was conducted at a private room next to the ART clinic to ensure the convenience of conducting a proper data collection.

\section{Data analysis}


SPSS version 22.0 was used for the statistical analysis of the validation study. The socio-demographic and clinical characteristics of women participants were presented descriptively in frequencies and percentages. For the reliability test, Cronbach alpha was used to show internal consistency. A Cronbach alpha greater than 0.60 was considered to be good (10). A correlation matrix of all the 12 items was computed and Kaiser-Meyer-Olkin and Bartlett's test was used to measure the sample adequacy. Moreover, a principal component analysis was conducted by using a Varimax rotation, and by Cattel's test, the eigenvalue was calculated in each of the extracted factors.

\section{Results}

\section{Reliability and internal consistency of PSS}

The internal consistency was evaluated by Cronbach's alpha and found to be 0.93 for the twelve items of PSS. All the items were included in the case processing and none of the items are eliminated throughout the list-wise procedure. Based on the assessment construct, this rate is higher than 0.80 , signifying that the items are homogenous but inter-dependent(11) as shown in the following Table 1.

Table 1: Principal Component Analysis of factor loading on PSS 


\begin{tabular}{|c|c|c|c|}
\hline \multirow{2}{*}{$\begin{array}{l}\text { Item } \\
\text { Number }\end{array}$} & \multirow[t]{2}{*}{ PSS Item } & \multicolumn{2}{|c|}{ Component } \\
\hline & & $\begin{array}{l}\text { Factor } \\
1\end{array}$ & $\begin{array}{l}\text { Factor } \\
2\end{array}$ \\
\hline & Esteem & & \\
\hline PSS 7 & $\begin{array}{l}\text { If I want to talk to somebody, I can turn to a friend/ or my partner and } \\
\text { he/she will listen to me. }\end{array}$ & $0.81 *$ & -0.07 \\
\hline PSS 9 & If I have problems my friend/partner would help me. & $0.79 *$ & 0.04 \\
\hline PSS 2 & $\begin{array}{l}\text { I feel I can count on my closest friends or partner when I need to be } \\
\text { listened to }\end{array}$ & $0.78 *$ & 0.06 \\
\hline \multirow[t]{2}{*}{ PSS 1} & I can freely express my opinion to my partner or group of friends & $0.72^{\star}$ & 0.02 \\
\hline & Self-development and belongingness & & \\
\hline PSS 6 & I think that my friends give me possibilities for growth. & $0.82^{\star}$ & -0.19 \\
\hline PSS 8 & $\begin{array}{l}\text { Most of the time, solutions to the problem presented by my group of } \\
\text { friends are useful. }\end{array}$ & $0.85^{\star}$ & -0.10 \\
\hline PSS 11 & Among my friend's conflicts are promptly resolved. & $0.84^{*}$ & -0.07 \\
\hline PSS 5 & To be part of a group of friends allows me to know myself better. & $0.82^{\star}$ & -0.21 \\
\hline PSS 12 & My friends have been able to give me affection when I have needed it. & $0.86^{*}$ & -0.13 \\
\hline PSS 4 & $\begin{array}{l}\text { If I ask for it, my friends can give me good advice for my personal } \\
\text { development. }\end{array}$ & $0.82^{*}$ & -0.15 \\
\hline PSS 10 & If something is for my good, my family will support me. & $0.57 *$ & $0.66^{*}$ \\
\hline PSS 3 & I feel emotionally sheltered by my family. & 0.39 & $0.81^{\star}$ \\
\hline
\end{tabular}

*Indicates item loading of greater than or equal to 0.40

\section{Construct validity}

The validity of this scale was examined by computing the correlation matrix of the PSS and HADS scores in the WLHIV and receiving the ART medication in Ethiopia. Based on the following criteria, the validity of the PSS among the WLHIV was established. (1) Eigenvalues are greater than or equal to 1, (2) meeting the criteria of scree Plot test, and (3) passing Bartlett's sphericity significance test. Therefore, based on the output of the Varimax rotation of these components were successfully loaded and factors were 
revealed to be valid since the initial eigenvalue met Kaiser criterion and was greater than 1, passed the Cattel's test of the scree plot of elbow criterion as shown in (Table 2) and (Figure 1) respectively.

Table 2: Factor analysis of a rotated component matrix of PSS

\begin{tabular}{|c|c|c|c|}
\hline \multirow{2}{*}{$\begin{array}{l}\text { Item } \\
\text { Number }\end{array}$} & \multirow[t]{2}{*}{ PSS Item } & \multicolumn{2}{|c|}{ Component } \\
\hline & & $\begin{array}{l}\text { Factor } \\
1\end{array}$ & $\begin{array}{l}\text { Factor } \\
2\end{array}$ \\
\hline & Esteem & & \\
\hline PSS 7 & $\begin{array}{l}\text { If I want to talk to somebody, I can turn to a friend/ or my partner and } \\
\text { he/she will listen to me. }\end{array}$ & 0.78 & 0.21 \\
\hline PSS 9 & If I have problems my friend/partner would help me. & 0.74 & 0.31 \\
\hline PSS 2 & $\begin{array}{l}\text { I feel I can count on my closest friends or partner when I need to be } \\
\text { listened to }\end{array}$ & 0.71 & 0.32 \\
\hline \multirow[t]{2}{*}{ PSS 1} & I can freely express my opinion to my partner or group of friends & 0.68 & 0.25 \\
\hline & Self-development and belongingness & & \\
\hline PSS 6 & I think that my friends give me possibilities for growth. & 0.84 & 0.10 \\
\hline PSS 8 & $\begin{array}{l}\text { Most of the time, solutions to the problem presented by my group of } \\
\text { friends are useful. }\end{array}$ & 0.83 & 0.19 \\
\hline PSS 11 & Among my friend's conflicts are promptly resolved. & 0.82 & 0.22 \\
\hline PSS 5 & To be part of a group of friends allows me to know myself better. & 0.84 & 0.09 \\
\hline PSS 12 & My friends have been able to give me affection when I have needed it. & 0.86 & 0.17 \\
\hline PSS 4 & $\begin{array}{l}\text { If I ask for it, my friends can give me good advice for my personal } \\
\text { development. }\end{array}$ & 0.82 & 0.14 \\
\hline PSS 10 & If something is for my good, my family will support me. & 0.31 & 0.82 \\
\hline PSS 3 & I feel emotionally sheltered by my family. & 0.09 & 0.89 \\
\hline
\end{tabular}

\section{Conclusion}

This validation of PSS is intended to examine the reliability and validity of Perceived social support (PSS) on WLHIV in Ethiopia. The provision of supportive interaction which is either emotional support, material support, informational support, or appraisal support to WLHIV was found to be an effective therapy to manage or adjust to the stressful events faced by patients. 
Overall, the internal consistency, reliability, and validity of the PSS scale of the Ethiopian version were found to be an application for WLHIV. Therefore, the establishment and introduction of this locally validated scale will be helpful for the proper assessment of the emotional, social, and psychological stance of WLHIV regarding the expected support. This would in turn contribute to health promotion approaches that emphasize the quality of life of the HIV patients and treatment adherence interventions.

\section{Declarations}

\section{Ethical consideration}

This study was approved by the Ethics committee of Jijiga University and the data was collected after obtaining informed consent from the participants.

\section{Availability of data}

The data set of this study is available and will be provided upon request by the corresponding author

\section{Funding}

This study has not received any financial support or grant from any organization and institution.

\section{Conflict of interest}

The authors declare that there is no competing interest.

\section{References}

1. Procidano ME HK. Measures of perceived social support from friends and from family: three validation studies. Am J Community Psychol. 1983;11(1):1-24.

2. Whitehead NE, Hearn LE, Burrell L. The Association Between Depressive Symptoms, Anger, and Perceived Support Resources Among Underserved Older HIV Positive Black/African American Adults. 2014;28(9):507-13.

3. Gupta J, Kapoor D, Sood V, Singh S, Sharma N, Kanwar P. Depression prevalence, its psychosocial and clinical predictors, in diabetes mellitus patients attending two health institutions of north India catering rural population. Indian J Psychiatry |. 2020;62(5).

4. Sarkhel S, Bakhla AK, Praharaj SK, Ghosal MK. Information overload regarding COVID - 19: Adaptation and validation of the cancer information overload scale. Indian J Psychiatry I. 2020;62(5):481-7.

5. Kulathunga M, Umayal S, Somaratne S, Srikanth S, Kathriarachchi S, Krd DS. Validation of the Geriatric Depression Scale for an elderly Sri Lankan clinic population. Indian J Psychiatry I. 2010;52(3):254-6. 
6. Shilpa Aggarwal, Col. H. R. A. Prabhu, Lt. Col. Aalok Anand LCAK. Stressful life events among adolecents: The development of a new measure. Indian J Psychiatry |. 2007;49(2).

7. Natamba BK, Achan J, Arbach A, Oyok TO, Ghosh S, Mehta S, et al. Reliability and validity of the center for epidemiologic studies-depression scale in screening for depression among HIV-infected and -uninfected pregnant women attending antenatal services in northern Uganda: a cross-sectional study. BMC Psychiatry. 2013;14(303):1-8.

8. Boc C, Dupret E. A validation study of the Hospital Anxiety and Depression Scale (HADS ) in a large sample of French employees. BMC Psychiatry. 2013;14(354):1-11.

9. Tran TD, Tran T, Fisher J. Validation of the depression anxiety stress scales ( DASS ) 21 as a screening instrument for depression and anxiety in a rural community-based cohort of northern Vietnamese women. BMC Psychiatry. 2013;13(24):1-12.

10. Nunnally J BI. Psychometric theory. New York: McGraw- Hill,. 1994.

11. Nunnally J. Psychometric theory. New York, McGraw-Hill. 1978.

\section{Figures}

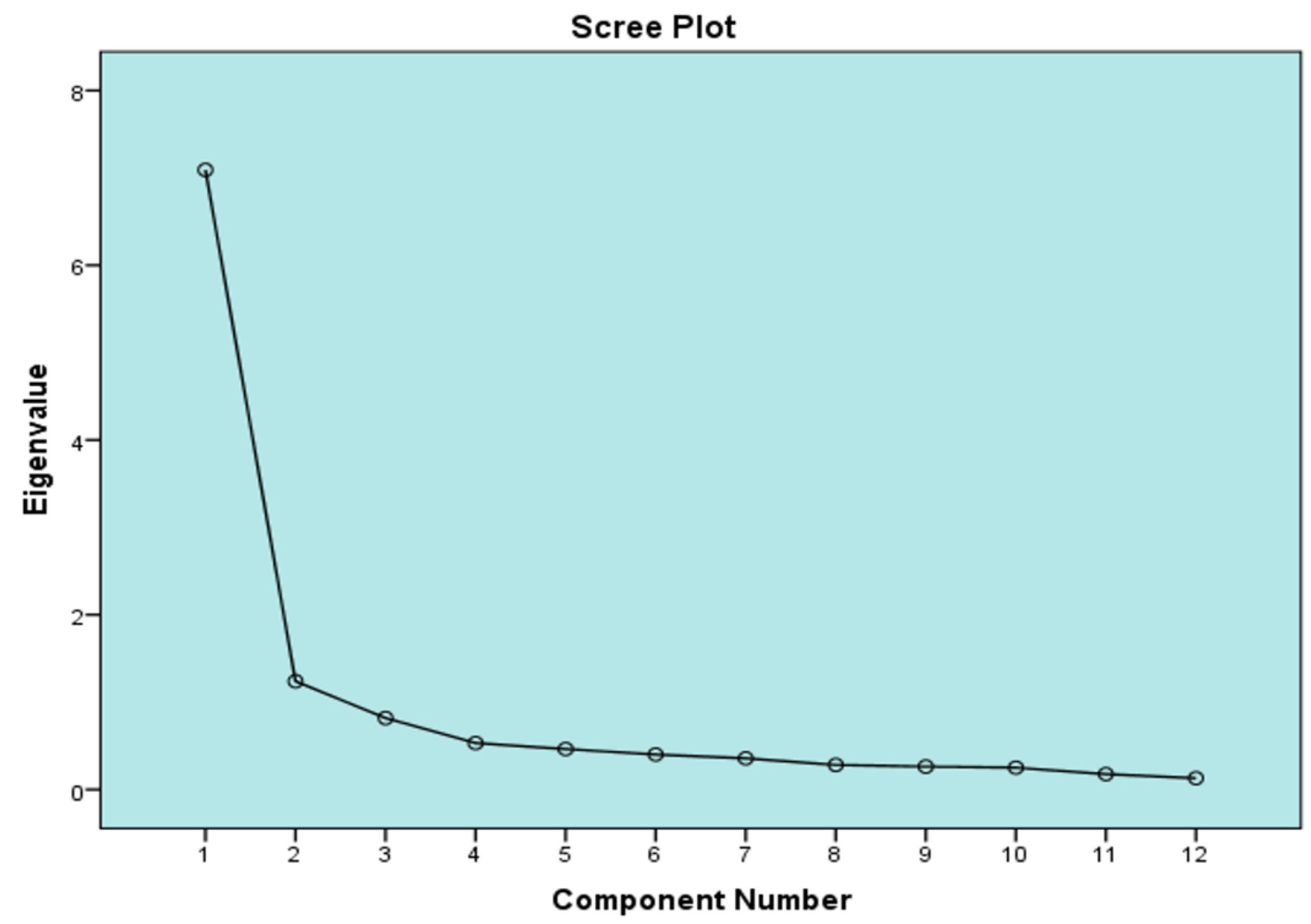




\section{Figure 1}

The scree plot of the components Perceived Social Support 